\title{
Protective Effect of Tert Butyl Hydroquinone on Diazinon-Induced Oxidative Stress in Brain and Heart of Male Rats
}

\author{
Saman Sargazi, ${ }^{1}$ Amir Moghadam-Jafari, ${ }^{2}$ and Mohammad Heidarpour ${ }^{3,}$ \\ ${ }^{1}$ Department of Biochemistry and Molecular Biology, Shahid Sadoughi University of Medical Sciences, Yazd, IR Iran \\ ${ }^{2}$ Department of Basic Sciences, Faculty of Veterinary Medicine, Ferdowsi University of Mashhad, Mashhad, IR Iran \\ ${ }^{3}$ Department of Clinical Sciences, Faculty of Veterinary Medicine, Ferdowsi University of Mashhad, Mashhad, IR Iran \\ "Corresponding author: Mohammad Heidarpour, Department of Clinical Sciences, Faculty of Veterinary Medicine, Ferdowsi University of Mashhad, Mashhad, IR Iran. E-mail: \\ heidarpour@um.ac.ir
}

Received 2015 January 08; Accepted 2015 May 22.

\begin{abstract}
Background: The present study was designed to investigate the chronic effects of diazinon on oxidative stress markers in brain and heart of rats and the possible protective effects of tert butyl hydroquinone (TBHQ), as an antioxidant.

Objectives: Therefore, the present study was undertaken to evaluate the protective role of TBHQ on oxidative stress induced by diazinon in brain and heart tissues of rats after 7 weeks exposure to sub-lethal dose of diazinon.

Materials and Methods: In this experimental study, 28 male Wistar rats which were randomly divided into four groups: diazinon group (10 mg/kg, once a day), TBHQ group $(0.028 \mathrm{~g} / \mathrm{kg}$ of diet, once a day), diazinon + TBHQ group (diazinon, $10 \mathrm{mg} / \mathrm{kg}$, once a day + TBHQ, $0.028 \mathrm{~g} / \mathrm{kg}$ of diet, once a day) and control group (corn oil, as vehicle of diazinon and TBHQ). The animals were treated with diazinon, TBHQ or corn oil orally using a stomach tube for 7 weeks.

Results: At the end of 7th week, total thiol groups, ferric reducing antioxidant power (FRAP) and malondialdehyde (MDA) levels in brain and heart tissues were investigated. A significant increase in MDA levels $(P=0.01)$ in heart tissue was evident in diazinon group, when compared to control group. Rats of the TBHQ and diazinon + TBHQ groups presented a significant increase in thiol groups $(\mathrm{P}=0.01$ ), when compared to control and diazinon groups. In addition, TBHQ administration significantly increased the FRAP level of brain tissue in TBHQ and TBHQ + diazinon groups, when compared with control and diazinon groups, respectively (P $=0.001$ ).

Conclusions: The results of the present study showed that TBHQ treatment could improve antioxidant status in brain and heart tissues of rats with chronic toxicity of diazinon. However, it could not ameliorate the lipid peroxidation sufficiently.
\end{abstract}

Keywords: Diazinon, Tert Butyl Hydroquinone, Oxidative Stress, Brain, Heart

\section{Background}

Population growth and consequently the increase in food consumption, especially agricultural products, have prompted farmers to increase their yields. Increasing planting, will consequently lead to the increase in using pesticides. One of the main concerns of the world health organization (WHO) is the uncontrolled use of pesticides in the agricultural industry [1] and exposure to pesticides is considered as a public health problem in rural areas [2]. Among the pesticides, organophosphates are commonly used which is due to their non-biodegradability decomposition and discontinuous nature [3]. Organophosphate pesticides generally have high toxicity and have a high potential to negatively act on non-target organisms. As a significant matter, poisoning from organophosphates is a major reason for the prevalence of disease and death in third world countries [4]. A number of factors such as dosage, way of exposure, absorption rate, physicochemi- cal properties and the level of neutralization of the toxin by the body, are involved in the intensity and duration of poisoning [5]. The main mechanism of pathogenicity in acute poisoning with organophosphate, is the irreversible inhibition of the enzyme acetylcholinesterase, which causes an accumulation of acetylcholine and acute muscarinic and nicotinic effects. However, in sub chronic or chronic poisoning by organophosphate, induction of oxidative stress is called as a central mechanism [6]. Oxidative stress represents an imbalance between the production of various free radicals of oxygen and the ability of the biological system for detoxification or repairing the damaging effects of their oxidative damages. Therefore, it will result in oxidative damages to the cell, texture, or organs of the body. Both increased production of reactive oxygen and decreased antioxidant capacity of the body may cause oxidative stress [7]. In several studies the role of oxidative stress in organophosphate-induced damage has been reported [8-13]. Diazinon (o, o-diethyl-o-[2-isopropyl- 
6-methyl-4-pyrimidinyl]phosphorothioate) is one of the most commonly used organophosphates in the world [14]. Diazinon affects mitochondrial membrane transportation and cytochrome P450 system in hepatocytes [15, 16]. Administration of diazinon to rats resulted in depletion of glycogen from the brain and peripheral tissues [17]. It has also been shown that diazinon caused an increase in lipid peroxidation in rat erythrocytes [18]. Diazinon treatment in rats decreased renal antioxidants and enhanced lipid peroxidation with concomitant renal damage, which are involved in the diazinon-induced renal oxidative stress and toxicity [19]. Anti-oxidants are substances that destroy the effects of free radicals in the body and prevent their acts. Antioxidants exist in some specific nutrients and neutralize free radicals. Tert butyl hydroquinone (TBHQ) is an organic aromatic compound which is derived from the hydroquinone. TBHQ is a powerful antioxidant which is used as an additive for unsaturated vegetable oils and many edible animal fats. TBHQ is able to induce the nuclear translocation of transcription factor NF-E2-related factor 2 (Nrf2), which in turn regulates the expression of vitagenes codifying for cytoprotective phase 2 antioxidant proteins, such as glutathione-S-transferase, $\mathrm{NAD}(\mathrm{P}) \mathrm{H}$ quinone oxidoreductase and heme-oxygenase-1 [20]. The use of this antioxidant in case of proving its protective effect could be a useful solution for the prevention of chronic toxicity in individuals who are exposed to the organophosphates, particularly the farmers. Combined effects of diazinon and TBHQ have not been studied before.

\section{Objectives}

Therefore, the present study was undertaken to evaluate the protective role of TBHQ on oxidative stress induced by diazinon in brain and heart tissues of rats after 7 weeks exposure to sub-lethal dose of diazinon.

\section{Materials and Methods}

\subsection{Chemiclas, Animals and Protocol Design}

In this experimental study, all the chemicals used in the present study were of technical grade and were supplied by Sigma-Aldrich (Germany) or Merk (Germany) companies.

Twenty eight adult male Wistar-rats, weighing in average 230 - $250 \mathrm{~g}$, which were purchased from the Razi Vaccine and Serum Research institute, Mashhad, Iran. The animals were acclimatized for one week before the onset of experiment. During the experiment, all ethical principles of animal testing were fully considered. The animals were housed in plastic (polypropylene) cages using paddy husk bedding at room temperature $\left(25 \pm 1^{\circ} \mathrm{C}\right)$ in a 12-hour light/dark cycle with $50 \pm 5 \%$ humidity. The animals had free access to commercial pellet diet (manufactured in Javaneh Khorasan, Mashhad, Iran) and water ad libitum. The experiment was approved by the Animal Welfare Committee of the School of the Veterinary Medicine, Ferdowsi University of Mashhad, Mashhad, Iran. The animals were randomly divided into 4 groups having 7 animals in each. The compounds were administrated in the morning (between 9:00 and 11:00 am) to non-fasted rats. All rats were treated for 7 weeks.

\subsection{Group 1, Control group}

That received corn oil (vehicle of diazinon and TBHQ) through gavages once a day.

\subsection{Group 2. Diazinon-Treated Group}

Diazinon at the dose of $10 \mathrm{mg} / \mathrm{kg} /$ day in corn oil was given through gavage to rats once a day. The selection of dose regimen was based on previously published studies which indicate substantial alterations in many of the biochemical parameters at this dose [14,19].

\subsection{Group 3. TBHQ Treated Group}

TBHQ at a dose of $0.028 \mathrm{~g} / \mathrm{kg}$ of diet was given through gavage to rats once a day. The selected dose of TBHQ was based on previously published studies which indicate antioxidative effects of TBHQ at this level [21]. The food intake of rats was measured during the acclimatization period. Preweighed food was provided in standard stainless steel hoppers. After 24 hours, the amount of food remaining, including any on the bottom of the cages or any that had spilled onto plastic sheets placed under each cage was recorded. Intake was calculated as the weight (in grams) of food provided less that recovered.

\subsection{Group 4, TBHQ + Diazinon-Treated Group}

TBHQ and diazinon (at above-mentioned doses) were administered orally via gavage needle.

\subsection{Tissue Sample Preparation and Biochemical Analysis}

The animals were euthanized by $\mathrm{CO}_{2} 24$ hours after the last oral administration. Brain and heart tissues of these animals were taken quickly, cleaned free of extraneous material and perfused immediately with sodium phosphate buffer $(\mathrm{pH}=7.4)$. Tissue samples were minced, cut into small pieces and then dried on a filter paper and homogenized (10\% w/v) in ice-cold $1.15 \% \mathrm{KCl}-0.01 \mathrm{M}$ sodium, potassium phosphate buffer $(\mathrm{pH}=7.4)$ by Silent crusher $\mathrm{M}$ type homogenizer (Heidolph Instruments $\mathrm{GmbH}$ and Co. KG, Schwabach, Germany). The homogenate was centrifuged 
at $18,000 \mathrm{~g}$ for 20 minutes at $4^{\circ} \mathrm{C}$, and the resultant supernatant was used for the determination of oxidative stress markers.

\subsection{MDA Assay}

The extent of lipid peroxidation was estimated as the concentration of thiobarbituric acid reactive product malondialdehyde (MDA) by using the method of Placer et al. [22]. The reaction mixture consisted of $0.2 \mathrm{~mL}$ of homogenized tissue, $1.3 \mathrm{~mL}$ of $0.2 \mathrm{M}$ Tris-0.16 $\mathrm{M} \mathrm{KCl}$ buffer $(\mathrm{pH}=$ 7.4) and $1.5 \mathrm{~mL}$ of thiobarbituric acid reagent. The mixture was heated in a boiling water bath for $10 \mathrm{~min}$. After cooling, $3 \mathrm{~mL}$ of pyridine/n-butanol (3: 1, v/v) and $1 \mathrm{~mL}$ of 1 normal sodium hydroxide were added and mixed by vigorous shaking. A blank was run simultaneously by incorporating $0.2 \mathrm{~mL}$ distilled water instead of the homogenized tissue. The absorbance of the test sample was read at 548 $\mathrm{nm}$. The nanomols of MDA per milliliter of homogenized tissue were calculated using $1.56 \times 105$ as extinction coefficient.

\subsection{Total Thiol Group Assay}

Total thiol groups of homogenized tissues were measured spectrophotometrically at 412 nm using DTNB [5, 5'dithiobis-(2-nitrobenzoic acid)] as the reagent [23]. After adding tris buffer to homogenized tissue, first absorbance was read at $412 \mathrm{~nm}$ (A1). Then DTNB was added and second absorbance at $412 \mathrm{~nm}$ was done (A2). The concentration of total thiol groups was calculated and expressed as $\mathrm{mmol} / \mathrm{L}$.

\subsection{FRAP Assay}

The total antioxidant capacity of the homogenized tissues was measured using FRAP assay, which depends upon the reduction of ferric tripyridyltriazine [Fe(III)-TPTZ] complex to the ferrous tripyridyltriazine [Fe (II)-TPTZ] by a reductant at low $\mathrm{pH}$. [Fe (II)-TPTZ] has an intensive blue color and can be monitored at $593 \mathrm{~nm}[24]$.

\subsection{Statistical Analysis}

Statistical analysis was conducted using SPSS for windows (Release 16, SPSS Inc., Chicago, IL) with a value of $P$ $<0.05$ as statistically significant. Data were expressed as mean \pm standard deviation (SD). One way ANOVA was used to compare means among the different groups. Following analysis of variance, significant between-group differences were detected by the Bonferroni test.

\section{Results}

A significant increase in MDA levels $(\mathrm{P}=0.01)$ in heart tissue was evident in the diazinon group, when compared to the control group. TBHQ alone or associated with diazinon, did not reduce lipid peroxidation, and no significant differences were observed for MDA level between TBHQ and control groups and between diazinon and diazinon + TBHQ groups (Table 1). No significant differences were found for total thiol groups between diazinon and control groups. However, rats of the TBHQ and diazinon + TBHQ groups presented a significant increase in thiol groups ( $P$ $=0.01)$, when compared to control and diazinon groups (Table 1). A significant increase $(P=0.013)$ in FRAP levels in heart and brain tissues was observed in the diazinon group, when compared to the control group. TBHQ administration significantly increased $(\mathrm{P}=0.001)$ the FRAP level of brain tissue in both TBHQ and TBHQ + diazinon groups, when compared with the control and diazinon groups, respectively (Table 1 ).

\section{Discussion}

Extensive application of organophosphates is usually accompanied with serious problems of pollution and health hazards. Organophosphates act as pro-oxidants and elicit oxidative effects in multiple organs. Reactive oxygen spices (ROS) are produced as the result of the metabolism of OPs by cytochrome P450s. Glycated proteins activate specific membrane receptors and induce an intracellular oxidative stress. In recent years, some agents with antioxidant effects (e.g. vitamins $\mathrm{C}$ and $\mathrm{E}, \mathrm{N}$-acetylcysteine and zinc) have been used to decrease cellular oxidative stress and thus cellular damage, in cases of organophosphate poisoning $[18,25]$. Tert-butylhydroquinone (TBHQ) is one of the few antioxidants permitted for use in foods. It has furthermore been shown to protect the living animal and cell lines against acute toxicity and oxidative results [2]. The present study was designed to elucidate changes of oxidative stress markers in heart and brain of rats following chronic administration of diazinon and the potential antioxidant effects of TBHQ, as a food-additive antioxidant. It has been shown that organophosphate intoxication produces oxidative stress by generation of ROS and free radicals and induces tissue lipid peroxidation [6]. In the present study, administration of $10 \mathrm{mg} / \mathrm{kg}$ of diazinon for 7 weeks induced lipid peroxidation in heart tissue. In consistent with the present study, Ogutcu et al. reported that diazinon (10 $\mathrm{mg} / \mathrm{kg}$, for 7 weeks) caused increase of MDA level of rat heart [26]. Enhanced lipid peroxidation induced by diazinon, has also been reported in other cells or tissues such as erythrocytes [27], liver [28] brain and spleen 
Table 1. Effects of Diazinon and TBHQ on the MDA, Total Thiol Groups and FRAP levels in Heart and Brain of Rats ${ }^{\mathrm{a}, \mathrm{b}}$

\begin{tabular}{|c|c|c|c|c|}
\hline Effects & $\operatorname{Control}(n=7)$ & $\operatorname{Diazinon}(\mathbf{n}=7)$ & TBHQ $(\mathbf{n}=7)$ & Diazinon-TBHQ $(\mathbf{n}=7)$ \\
\hline \multicolumn{5}{|l|}{ MDA, nmol/L } \\
\hline Brain & $6.01 \pm 1.02^{\mathrm{b}, \mathrm{c}}$ & $6.83 \pm 0.99^{\mathrm{b}, \mathrm{c}}$ & $5.55 \pm 0.88^{b}$ & $7.30 \pm 0.68^{c}$ \\
\hline Heart & $3.77 \pm 0.82^{\mathrm{b}}$ & $7.55 \pm 1.04^{\mathrm{b}}$ & $5.30 \pm 0.32^{\mathrm{b}}$ & $6.48 \pm 1.12^{\mathrm{c}, \mathrm{d}}$ \\
\hline \multicolumn{5}{|c|}{ Total thiol groups, $\mathrm{mmol} / \mathrm{L}$} \\
\hline Brain & $0.34 \pm 0.09^{\mathrm{b}}$ & $0.31 \pm 0.06^{\mathrm{b}}$ & $0.51 \pm 0.08^{c}$ & $0.55 \pm 0.12^{c}$ \\
\hline Heart & $0.32 \pm 0.04^{\mathrm{b}}$ & $0.27 \pm 0.05^{b}$ & $0.48 \pm 0.11^{\mathrm{c}}$ & $0.55 \pm 0.08^{c}$ \\
\hline \multicolumn{5}{|c|}{ FRAP, mmol/L } \\
\hline Brain & $1.18 \pm 0.07^{\mathrm{b}}$ & $1.34 \pm 0.09^{c}$ & $1.35 \pm 0.04^{\mathrm{c}}$ & $1.50 \pm 0.10^{\mathrm{d}}$ \\
\hline Heart & $1.23 \pm 0.04^{\mathrm{b}}$ & $1.37 \pm 0.08^{\mathrm{c}, \mathrm{d}}$ & $1.27 \pm 0.09^{\mathrm{b}, \mathrm{c}}$ & $1.45 \pm 0.07^{\mathrm{d}}$ \\
\hline
\end{tabular}

Abbreviation: FRAP, ferric reducing antioxidant power; MDA, malondialdehyde; TBHQ, tert butyl hydroquinone.

${ }^{\mathrm{a}}$ Values are expressed as mean $\pm \mathrm{SD}$.

${ }^{\mathrm{b}}$ Means within rows lacking a common lowercase letters $(\mathrm{b}, \mathrm{c}, \mathrm{d})$ differ $(\mathrm{P}<0.05)$.

[29] and pancreas [30]. The severity of diazinon-induced lipid peroxidation in different tissues depends on several factors such as oxygen consumption, metabolic activity rate and susceptibility to oxidants [29]. The use of antioxidants has been suggested as one of the methods of dealing with the toxicity of organophosphates in various studies $[18,25,26,31]$. TBHQ is a derivative of hydroquinone, substituted with tert-butyl group. TBHQ is a highly effective antioxidant. In foods, it is used as a preservative for unsaturated vegetable oils and many edible animal fats. In the present study, TBHQ treatment improved antioxidant status in heart and brain tissues of rats. Rats of the TBHQ and diazinon + TBHQ groups presented a significant increase in total thiol groups and FRAP levels. TBHQ is a very potent activator of Nrf2 transcription factor, which has an important role in enzyme defending of the cells against the oxidative agents. However, it has been found that its antioxidant mechanism is mostly due to autophagy process to happen by AMP-activated protein kinase (AMPK) factor that through this mechanism, protects cells from lipotoxicity and is considered as a beneficial antioxidant [32, 33]. The dosage of TBHQ used in the present study was selected based on recommendations in the AIN-93G formula [34]. Several limitations of the present study especially the low amount of TBHQ administrated to rats and also the low number of animals in each group might be responsible for the observed results.

The present study is the first investigation in which the protective effects of TBHQ was evaluated against diazinoninduced oxidative stress in brain and heart of rats. TBHQ increased antioxidant levels in rats receiving diazinon. However, it could not attenuate diazinon-induced lipid peroxidation. The total antioxidant defense mechanism was not able to protect the tissues from lipid peroxidation caused by diazinon. Using higher amounts of TBHQ might be able to ameliorate diazinon-induced lipid peroxidation

\section{Acknowledgments}

This study was supported by research fund of Ferdowsi University of Mashhad (project no. 3/29214). The authors wish to thank technicians who kindly helped us for sample collection of this study.

\section{Footnotes}

Authors' Contribution: All authors had equal role in design, work, statistical analysis and manuscript writing.

Conflict of Interest: The authors declare there is no conflict of interests.

Funding/Support: Ferdowsi University of Mashhad.

\section{References}

1. Ahmadi S, Jafari M, Asgari A, Salehi M. Acute effect of diazinon on lipid peroxidation level and activities of antioxidant enzymes in rat spleen. J Kermanshah Univ Med Sci. 2012;16(1):1-9.

2. Joursaraei S, Beyki AA, Yousefnia PYR, Alizadeh NR. The in-vitro effects of hinosan and diazinon on human sperm parameters. 2005

3. Solati A, Tavasoly A, Koohi MK, Marjanmehr SH, Rezvanjoo B. Effects of dermal exposure to chlorpyrifos on liver and brain structures and biochemical parameters in rabbits. Comparative Clinical Pathology. 2011;21(6):1211-7. doi: 10.1007/s00580-011-1267-7.

4. Bonilla E, Hernandez F, Cortes L, Mendoza M, Mejia J, Carrillo E, et al. Effects of the insecticides malathion and diazinon on the early oogenesis in mice in vitro. Environ Toxicol. 2008;23(2):240-5. doi: 10.1002/tox.20332. [PubMed: 18214912]. 
5. Buyukokuroglu ME, Cemek M, Tosun M, Yurumez Y, Baş O, Yavuz Y. Dantrolene may prevent organophosphate-induced oxidative stress and muscle injury. Pestic Biochem Physiol. 2008;92(3):156-63.

6. Lukaszewicz-Hussain A. Role of oxidative stress in organophosphate insecticide toxicity-Short review. Pesticide biochemistry and physiology. 2010;98(2):145-50.

7. Quistad GB, Sparks SE, Casida JE. Fatty acid amide hydrolase inhibition by neurotoxic organophosphorus pesticides. Toxicol Appl Pharmacol. 2001;173(1):48-55. doi: 10.1006/taap.2001.9175. [PubMed: 11350214].

8. Agrawal A, Sharma B. Pesticides induced oxidative stress in mammalian systems: a review. Int J Biol Med Res. 2010;1(3):90-104.

9. Delgado EH, Streck EL, Quevedo JL, Dal-Pizzol F. Mitochondrial respiratory dysfunction and oxidative stress after chronic malathion exposure. Neurochem Res. 2006;31(8):1021-5. doi: 10.1007/s11064-006-9111-1. [PubMed: 16865556].

10. Mashali AA, Nounou HA, Sharara GM, Manal H, Aziz A. Role of oxidative stress and apoptosis into acute organophosphorus intoxicated patients. J Med Res Inst. 2005;26:255-63.

11. Kovacic P. Mechanism of organophosphates (nerve gases and pesticides) and antidotes: electron transfer and oxidative stress. Curr Med Chem. 2003;10(24):2705-9. [PubMed: 14529460].

12. Zhou JF, Xu GB, Fang WJ. Relationship between acute organophosphorus pesticide poisoning and damages induced by free radicals. Biomed Environ Sci. 2002;15(2):177-86. [PubMed:12244759].

13. Banerjee BD, Seth V, Ahmed RS. Pesticide-induced oxidative stress: perspectives and trends. Rev Environ Health. 2001;16(1):1-40. [PubMed: 11354540].

14. Kalender S, Ogutcu A, Uzunhisarcikli M, Acikgoz F, Durak D, Ulusoy $\mathrm{Y}$, et al. Diazinon-induced hepatotoxicity and protective effect of vitamin E on some biochemical indices and ultrastructural changes. Toxicology. 2005;211(3):197-206. doi: 10.1016/j.tox.2005.03.007. [PubMed: 15925023].

15. Nakagawa Y, Moore G. Role of mitochondrial membrane permeability transition in p-hydroxybenzoate ester-induced cytotoxicity in rat hepatocytes. Biochemical pharmacol. 1999;58(5):811-6.

16. Sams C, Cocker J, Lennard MS. 544 Metabolism of chlorpyrifos and diazinon by human liver microsomes. Toxicology Letters. 2003;144:s146.

17. Matin MA, Sattar S, Husain K. The role of adrenals in diazinon-induced changes in carbohydrate metabolism in rats. Arh Hig Rada Toksikol. 1990;41(4):347-56. [PubMed: 2092650].

18. Sutcu R, Altuntas I, Buyukvanli B, Akturka O, Ozturka O, Koylu H, et al. The effects of diazinon on lipid peroxidation and antioxidant enzymes in rat erythrocytes: role of vitamins $\mathrm{E}$ and C. Toxicol Ind Health. 2007;23(1):13-7. [PubMed: 17722735].

19. Shah MD, Iqbal M. Diazinon-induced oxidative stress and renal dysfunction in rats. Food Chem Toxicol. 2010;48(12):3345-53. doi: 10.1016/j.fct.2010.09.003. [PubMed: 20828599].

20. Tasset I, Perez-De La Cruz V, Elinos-Calderon D, Carrillo-Mora P, Gonzalez-Herrera IG, Luna-Lopez A, et al. Protective effect of tertbutylhydroquinone on the quinolinic-acid-induced toxicity in rat striatal slices: role of the Nrf2-antioxidant response element path- way. Neurosignals. 2010;18(1):24-31. doi: 10.1159/000243650. [PubMed: 19797933].

21. Nishizono S, Hayami T, Ikeda I, Imaizumi K. Protection against the diabetogenic effect of feeding tert-butylhydroquinone to rats prior to the administration of streptozotocin. Biosci Biotechnol Biochem. 2000;64(6):1153-8.

22. Placer ZA, Cushman LL, Johnson BC. Estimation of product of lipid peroxidation (malonyl dialdehyde) in biochemical systems. Analytical biochem. 1966;16(2):359-64.

23. Hu ML. Measurement of protein thiol groups and glutathione in plasma. Methods Enzymol. 1994;233:380-5. [PubMed: 8015473].

24. Benzie IF, Strain JJ. The ferric reducing ability of plasma (FRAP) as a measure of "antioxidant power": the FRAP assay. Anal Biochem. 1996;239(1):70-6. doi: 10.1006/abio.1996.0292. [PubMed: 8660627].

25. El-Shenawy NS, El-Salmy F, Al-Eisa RA, El-Ahmary B. Amelioratory effect of vitamin E on organophosphorus insecticide diazinon-induced oxidative stress in mice liver. Pesticide biochemistry and physiology. 2010;96(2):101-7.

26. Ogutcu A, Uzunhisarcikli M, Kalender S, Durak D, Bayrakdar F, KalenderY. The effects of organophosphate insecticide diazinon on malondialdehyde levels and myocardial cells in rat heart tissue and protective role of vitamin E. Pest biochem physiol. 2006;86(2):93-8.

27. Altuntas I, Kilinc I, Orhan H, Demirel R, Koylu H, Delibas N. The effects of diazinon on lipid peroxidation and antioxidant enzymes in erythrocytes in vitro. Hum Exp Toxicol. 2004;23(1):9-13. [PubMed: 15027810].

28. Amirkabirian N, Teimouri F, Esmaily H, Mohammadirad A, Aliahmadi A, Abdollahi M. Protection by pentoxifylline of diazinoninduced toxic stress in rat liver and muscle. Toxicol Mech Methods. 2007;17(4):215-21. doi: 10.1080/15376510600943783. [PubMed: 20020971].

29. Jafari M, Salehi M, Ahmadi S, Asgari A, Abasnezhad M, Hajigholamali $M$. The role of oxidative stress in diazinon-induced tissues toxicity in Wistar and Norway rats. Toxicol Mech Methods. 2012;22(8):638-47. doi: 10.3109/15376516.2012.716090. [PubMed: 22871176].

30. Gokalp O, Buyukvanlı B, Cicek E, Ozer M, Koyu A, Altuntas I, et al. The effects of diazinon on pancreatic damage and ameliorating role of vitamin E and vitamin C. Pest biochem physiol. 2005;81(2):123-8.

31. Cankayali I, Demirag K, Eris O, Ersoz B, Moral AR. The effects of $\mathrm{N}$-acetylcysteine on oxidative stress in organophosphate poisoning model. Adv Ther. 2005;22(2):107-16. [PubMed: 16020401].

32. Lu XY, Wang HD, Xu JG, Ding K, Li T. Pretreatment with tertbutylhydroquinone attenuates cerebral oxidative stress in mice after traumatic brain injury. J Surg Res. 2014;188(1):206-12. doi: 10.1016/j.jss.2013.11.1106. [PubMed: 24387843].

33. Eftekharzadeh B, Maghsoudi N, Khodagholi F. Stabilization of transcription factor Nrf2 by tBHQ prevents oxidative stress-induced amyloid beta formation in NT2N neurons. Biochimie. 2010;92(3):245-53. doi: 10.1016/j.biochi.2009.12.001. [PubMed: 20026169].

34. Reeves PG, Nielsen FH, Fahey GJ. AIN-93 purified diets for laboratory rodents: final report of the American Institute of Nutrition ad hoc writing committee on the reformulation of the AIN-76A rodent diet.J Nutr. 1993;123(11):1939-51. [PubMed: 8229312]. 